Accessing emergency contraception pills from pharmacies: the experience of young women in London

Gillian A O Turnbull*; BA, MSc

Independent; Vancouver, Canada

e-mail: gorlikowturnbull@gmail.com

Rachel H Scott; MSc, PhD

Department of Epidemiology and Population Health, London School of Hygiene and Tropical Medicine, London, UK.

Sue Mann; MFSRH, MFPHM

Medical Expert in Reproductive Health, Public Health England, London, UK.

Kaye Wellings; MA, MSc, FRCOG, FFPH, FFRSH, FAcSS

Department of Public Health and Policy, London School of Hygiene \& Tropical Medicine, London, UK.

*Corresponding author

Word count: 3045 (reduced from 3850) 


\section{Abstract 189}

\section{Introduction}

Over-the-counter provision of emergency contraception pills (ECP) has increased since deregulation of progestogen-only formulations and is now the most common public health service provided by UK pharmacists. Important questions relate to women's perceptions of their experience of receiving ECPs from pharmacists.

\section{Methods}

Qualitative study: in-depth interviews with young women reporting ECP use, recruited from clinic (10); pharmacy (6), and community settings (5) in London.

\section{Results}

Key advantages of pharmacy provision were ease and speed of access and convenience. Disadvantages included a less personal service, inadequate attention to information needs and to prevention of recurrence of ECP need, and unsupportive attitudes of pharmacy staff. Suggested service improvements included increasing privacy, providing more contraceptive advice, adopting a more empathetic approach and signposting follow-up services.

\section{Conclusion}

Pharmacies are important in the choice of settings from which ECPs can be obtained and many aspects of pharmacy provision are appreciated by young women. There is scope to further enhance pharmacists' role. 


\section{Key messages}

- Pharmacy ECP provision has advantages for young women, notably convenience.

- Women tended to report less supportive attitudes, more cursory consultations and insufficient privacy, in pharmacies compared to clinics.

- Pharmacies have considerable potential to improve access to, and prevent further need for, ECP use by young women. 


\section{Introduction}

Emergency contraception pills (ECPs) can prevent unintended pregnancy after unprotected sex. Recent decades have seen major changes in access, in part facilitated by the development of progestogen-only formulations available over the counter (OTC). Pharmacy provision has the potential to increase access to ECPs[1-2] and its use has grown in Britain, most markedly among younger women and those accessing retail outlets[3].

ECPs can be purchased OTC, or supplied under Patient Group Directions (PGD) which allow specified medicines to be supplied to certain patients, without the need for clinical consultation[4]. Given their expanded role in providing ECPs, important questions relate to the quality of care women receive from pharmacies. Quantitative studies[5-6] have shown that client satisfaction varies between clinics and pharmacies. Women using clinics feel more comfortable and better informed about contraceptive options, while pharmacies are valued for speed and convenience.

Few qualitative studies have explored satisfaction and most have used simulated patients [7]. Understanding users' experiences is crucial to leveraging the potential of pharmacies in supplying ECP and realising its benefits in preventing unintended pregnancy. Here we report on young women's experiences of accessing ECPs from pharmacies and sexual health clinics.

\section{Methods}

\section{Sampling}

In 2017, 2 I participants were recruited, from a young person's sexual health clinic (YPSHC) in North London (10); from five pharmacies across central London (6) and by snowballing (5) (Table I). Inclusion criteria were: age 16-25; English speaking; and self-reporting at least one pregnancy scare (defined as "any time you were worried you may be pregnant when you didn't want to be") or ECP use. In the YPSHC, patients were approached to explain the research aims, confirm they met the inclusion criteria and take contact details from those interested in participating, over a three week period. In pharmacies, during a six month span, leaflets describing the study were given to women collecting ECPs with the option of contacting the researcher directly or having the researcher follow-up. Women recruited via snow-balling, whereby those who knew of the research or had been interviewed approached others they knew to be eligible, were invited to contact the researchers for information. Recruitment occurred at various times of day to ensure the sample represented a range of activities. Interviews were analysed until thematic saturation occurred and no new themes emerged. 
ITable I Summary characteristics of women interviewed

\begin{tabular}{|l|l|l|l|}
\hline Participant & \multicolumn{1}{|c|}{ Age } & \multicolumn{1}{c|}{ Educational Level } & Recruitment Site \\
\hline I & 19 & Secondary School & Clinic \\
\hline $\mathbf{2}$ & 16 & Secondary School Student & Clinic \\
\hline $\mathbf{3}$ & 21 & University Student & Clinic \\
\hline $\mathbf{4}$ & 24 & Secondary school & Clinic \\
\hline $\mathbf{5}$ & 22 & Higher education & Clinic \\
\hline $\mathbf{6}$ & 19 & University student & Clinic \\
\hline $\mathbf{7}$ & 21 & Secondary school & Clinic \\
\hline $\mathbf{8}$ & 20 & Secondary school & Clinic \\
\hline $\mathbf{9}$ & 24 & Higher education & Clinic \\
\hline $\mathbf{1 0}$ & 21 & Higher education & Clinic \\
\hline $\mathbf{1 1}$ & 24 & Higher education & Community \\
\hline $\mathbf{1 2}$ & 24 & Higher education & Community \\
\hline $\mathbf{1 3}$ & 25 & Higher education & Community \\
\hline $\mathbf{1 4}$ & 24 & Higher education & Community \\
\hline $\mathbf{1 5}$ & 25 & Higher education & Community \\
\hline $\mathbf{1 6}$ & 20 & University Student & Community \\
\hline $\mathbf{1 7}$ & 25 & Higher education & Community \\
\hline $\mathbf{1 8}$ & 21 & University Student & Community \\
\hline $\mathbf{1 9}$ & 22 & Higher education & Community \\
\hline $\mathbf{2 0}$ & 23 & Higher education & Community \\
\hline $\mathbf{2 1}$ & 25 & Higher education & Community \\
\hline
\end{tabular}

\section{Data collection}

Women recruited in the YPSHC were interviewed in a private room, others at a place of their choosing. Two interviews were conducted by phone. Participants were given information sheets and consent forms and the confidentiality protocol and right to opt-out at any point was explained. Topic-guides covered use of ECPs, the circumstances and experience of accessing it in clinic or pharmacy and, if obtained from both, any differences experienced by setting, and suggested improvements for pharmacy provision. $£ 20$ retail vouchers were given in appreciation. Interviews were recorded with participants' permission and transcribed. Unique numbers were used to identify participants.

\section{Analysis}

Modified thematic analysis in several stages (familiarisation with the data followed by generation of codes) was used to identify and categorise key themes emerging from the data[8]. The coding framework was developed iteratively and collaboratively. The research team met regularly to review transcripts, identify themes and categories relevant to the 
research questions, and ensure inter-rater reliability. Within major thematic categories relating to the research questions, emerging themes were arranged into taxonomies.

\section{Results}

All participants reported having used ECPs, the majority more than once. Many had obtained ECPs from both pharmacies and YPSHCs, facilitating comparison of experiences within and between accounts. Some had purchased ECPs and others had obtained it free of charge. Overarching themes emerging from data analysis were: convenience; privacy and confidentiality; quality of service; and staff attitudes.

\section{Convenience}

Convenience was a key advantage of pharmacies. They were located within the community, close-by, open for longer hours, and visited for other purchases. YPSHCs, with more restricted hours, longer waiting times and often requiring an appointment, compared less favourably: 'It (YPSHC) took me three hours to get an appointment and it's far away, whereas the pharmacy is at the bottom of my road'. '...I went in my lunch hour' 'In my road there's about three pharmacies and they're all open late'.

\section{Privacy and confidentiality}

The public nature of pharmacies was considered a drawback in terms of visibility. Women seeking ECPs often found themselves queuing alongside diverse shoppers: 'the only other people that go there are old men with chesty coughs. It's just like we know why he's there and we know why she's there'; 'People ... might be paying for a pair of tights and you're there asking for (ECPs)'.

Women took measures to avoid being recognised, both by acquaintances and, in the case of a return visit, by the pharmacists themselves.

'I didn't want to do the one that was too close to my house so I did it with (High Street pharmacy) further up the road and the third time I was too embarrassed to come back here again so I went to a different (one). (5)

The specialist nature of clinics was considered an advantage; the common purpose among attenders removed concerns of being observed. 'If you're in the [YPSHC] ...you see someone you know it's like, OK, we're all here for the same reason'. Being among age-peers was further reassurance; a 16 year-old reported feeling more comfortable at the clinic alongside fellow students.

The public nature of pharmacies was a downside. Even when women were taken to a separate area for the consultation, the interaction still took place within earshot of others. That the 
consultation area was separate drew attention to the reason for attending, contrasting unfavourably with clinics; 'it makes a huge difference where you're in a room with a shut door'.

\section{Quality of service}

Overall, the service received at pharmacies was experienced as less personal 'They don't know me, they don't know my history'; 'I remember the lady seemed quite cold and medical about it, when I go to the doctors I feel like I've been spoken to like a human being rather than a number on a sheet'; 'The (YPSH) it's a bit more open. Once we went to (pharmacy) to get it, it was more, like distant... As a consumer it feels a bit cold...'

The more personal approach in clinics was attributed partly to staff being more experienced in interpersonal communication with young people; 'that's their job and that's what they're there to do... the pharmacy is like a wide range of people'. It was recognised as the downside of the timesaving afforded by pharmacies. Nevertheless, some felt disconcerted by the haste with which they were treated.

'... it's not a pleasant experience. . ...it was just really quick, in and out... Whereas in (YPSHC), ... that's all they do every day - younger people, I feel like they cared about it a bit more'. (I5)

Information gathering in the pharmacy was described as 'a tick box exercise'; 'a checklist of things that need to get done'. Again this was attributed to lack of time in busy retail settings.

'...they're busy behind the till and actually have to take five minutes out and ask all these questions and I think it's probably a bit of a pain in the bum for them'. (I7)

One participant noted that the need for ECPs might have stemmed from a traumatic experience, and that failure to 'dig that little deeper' missed a potential opportunity.

... it's an emergency isn't it? A morning after pill is never a situation you choose to be in. There could be a horrible situation around it, something that needs to be explored. So that might be the point at which to combat something that could potentially cause a problem again. (I I)

GPs are really well versed in safeguarding and things like that, but pharmacists maybe less so, and again it goes back to the busy point. (17)

Not all women felt that their needs were met within pharmacies. Information was not always sought on contraceptive use, a commonplace at clinics. This was not the experience of all women: 
'They (pharmacies) have always prepped me with the information that I needed to know and then would ask me if I wanted to take it home or have it there and I always had it there... They always said if anything happens ... just to come back. (5)

For some, the pared-down approach was the reason for choosing the pharmacy: 'the less of a deal it feels like ...the better'; 'I didn't really want to sit and discuss it... I just answered their questions and went'. One participant, aged 23 , considered detailed questioning an unwelcome intrusion.

it was almost like I had to justify why I needed it and I felt that was my private information (...) if I'd wanted to talk to a doctor I would have gone to the clinic". (20)

The variability in information needs was mentioned in several accounts, younger women and first-time users being seen as possibly benefitting from the more comprehensive approach and discursive style of the clinic than older women or those who had used ECPs previously.

\section{Staff attitudes}

The most commonly mentioned reservation relating to pharmacies as ECP sources were staff attitudes. Some had positive experiences but others described the response of staff as judgmental, unsympathetic and unsupportive; '..looked at me like I was a weirdo or something..'; 'They shame you, ...they don't ask why but it's just like OK please stand to the side'.

'It was not a nice experience because the chemist was really judgmental, maybe because of my age. Asked me the questions but kind of just looking down on me.... have you done this, have you been with this person for a long time, and I was like, yeah, l've been with him for a few months, and he was like, that's not a long time, very judgmental. (I8)

Again, this was contrasted with the YPSHC:

'...the fact that I still remember it so well, they gave such a good experience.... They asked questions, but I didn't feel judged at all. I was more comfortable there (YPSHC). (4)

The accounts of some women, however, suggested that the attitudes described were to some extent their own, that they felt ashamed to be obtaining ECP, especially in cases of repeat use:

'It's going to sound bad but maybe three or four times?'.

...there's something about being, oh l've been shit, I've allowed this to happen, I shouldn't have put myself in this situation. A self-blame thing. Yeah, so I think the act itself of getting it was fine it was just my own personal feelings around it. (13) 
Even so, there was little indication that reassurance had been provided by pharmacists: 'You play it down ... so they might've just been playing on the fact that I was relaxed but I wasn't really relaxed and they didn't make me feel any more relaxed'. (2I)

The gender of pharmacists was raised as an issue. For the most part, clinic staff were women and pharmacists were men and this seemed to increase feelings of discomfort.

\section{Women's recommendations}

Women's recommendations for improvements to pharmacy services closely mirrored their misgivings. Suggestions included having pharmacists explore reasons for seeking ECPs, ask about current and future contraception, and signpost to follow-up services. An older participant made an eloquent case for equivalence of standards-of-care between pharmacies and other providers.

As long as the pharmacies are taking on that responsibility, they need to follow it through in a way that the GP might...It's the same pill, it's a similar emotional experience, so it should be treated the same level of delicacy. If there's going to be a push for pharmacies to take more of a role in contraception (you have to be sure they're) alright with it. (I7)

Suggestions for ways of making the experience more discreet included a system modelled on the CCard (comecorrect.org.uk), whereby free condoms can be obtained at participating outlets including some pharmacies, and the "Ask for Angela" initiative (met.police.uk/AskforAngela), where individuals feeling unsafe can alert staff in participating venues. A non-disclosive code word to give to the pharmacist could signal that a customer wanted ECPs but did not want this to be public.

\section{Discussion}

These data demonstrate undoubted advantages of pharmacies for prompt and accessible ECPs provision. They also reveal disadvantages experienced by some in terms of staff attitudes, a more fleeting consultation and less preventive advice.

A strength of the study is that data were collected from actual patients, many of whom were able to make comparisons between obtaining ECPs from different sources. A weakness is the limited geographical setting and small sample.

Quantitative studies elsewhere $[9,5,10]$ have similarly shown support for pharmacy access to ECPs for reasons of speed and convenience but with reservations regarding patient interaction[6], data gathering and provision of advice[ I I]. In research on pharmacy provision of ECPs in Australia, clinical assessment met all requirements in only one-in-five consultations, and provision of information in two-in-five[5]. The findings of qualitative studies have been more equivocal. A mystery-client survey found that pharmacists were generally kind and 
efficient, although some instances of judgmental attitudes were reported[I3]. A study of women's experience of accessing pharmacies, an evaluation of local PGDs in the North of England, were somewhat divergent from ours; judgmental attitudes among pharmacists were rarely encountered[12]. However, this was a pilot scheme and, crucially, was preceded by extensive preparation and training for pharmacists. It also included women of all ages and younger women may be more likely to perceive stigma.

Lessons to be drawn for policy and practice must recognise the constraints of the pharmacy as a setting for supplying ECP. The detailed history taking and contraceptive counselling that is possible in YPSHCs may be more difficult in a busy retail outlet. The benefits of longer interaction are likely offset by costs in terms of speed, the attribute most highly valued by women. Nevertheless, modifications which would address women's concerns are unlikely to be time-consuming. They include the option of speaking to a woman pharmacist where possible; the need for discretion in the transaction and, perhaps most importantly, the need for a neutral but sympathetic approach.

The evidence from this and other studies highlights the importance of professional support and training. Research has shown that although pharmacists have positive attitudes towards providing public health services, they are generally under-confident in doing so[9, 14-16]. Current guidance[17] and accredited e-learning programmes (https://www.cppe.ac.uk/programmes///ehc-e-03) provide advice to pharmacists on technical, legal and safeguarding aspects of provision, and on the need for sensitivity[18]. A review of training content and methodologies mapped against identified gaps may help equip pharmacists with the communication skills they need to explore wider psychosocial contexts and identify ongoing contraceptive needs[5].

Pharmacies occupy an important place in the range of settings in which ECPs can be obtained, and so provide essential choice in contraceptive provision. The challenge identified in this study is harnessing the potential of pharmacy supply of ECPs and achieving optimal equivalence of care, whilst retaining the qualities which make pharmacies attractive to women in the first place.

\section{Ethics committee approval}

This study was approved by the London School of Hygiene and Tropical Medicine (LSHTM) MSc Research Ethics Committee (ref: 10823), the LSHTM Observational/Interventions Research Ethics Committee (ref: 13420) and the clinical governance lead for the high street pharmacies.

\section{Patient and Public Involvement Statement}


The young person's clinic is not under the direction of the NHS. The management and clinical team at the centre reviewed and approved the project. Participants reviewed and signed consent forms before interviews began.

\section{Funding}

This research was part funded by a grant from the Health Protection Research Units. 


\section{References}

I Landau SC, Tapias MP, Mcghee BT. Birth control within reach: a national survey on women's attitudes toward and interest in pharmacy access to hormonal contraception. Contraception 2006Oct25;74(6):463-70.

2 Raymond EG, Trussell J, Polis CB. Population Effect of Increased Access to Emergency Contraceptive Pills. Obstet Gynecol 2007; 109(I): |8I-8.

3 Black K, Geary R, French R, et al. Trends in the use of emergency contraception in Britain: evidence from the second and third National Surveys of Sexual Attitudes and Lifestyles. BJOG 2016;123(10):1600-7.

4 NHS, Patient Group Directions. 2019. https://www.england.nhs.uk/south/infoprofessional/pgd/.

5 Queddeng K, Chaar B, Williams K. Emergency contraception in Australian community pharmacies: a simulated patient study. Contraception 20I I;83(2): I76-82.

6 Gonsalves L, Hindin MJ. Pharmacy provision of sexual and reproductive health commodities to young people: a systematic literature review and synthesis of the evidence. Contraception 2017;95(4):339-63.

7 Higgins SJ, Hattingh HL. Requests for emergency contraception in community pharmacy: an evaluation of services provided to mystery patients. Res Social Adm Pharm 20।3;9(I):I|4-9.

8 Braun V, Clarke V. Using thematic analysis in psychology. Qual Res Psychol 2006;3(2):77-I0I.

9 Foster DG, Landau SC, Monastersky N, et al. Pharmacy access to emergency contraception in California. Perspect Sex Reprod Health 2006 Mar;38(I):46-52.

10 Aneblom G, Larsson M, von Essen L, Tydén T. Women's voices about emergency contraceptive pills "over-the-counter": a Swedish perspective. Contraception 2002;66(5):339-43.

I I Gainer E, Blum J, Toverud EL, et al. Bringing emergency contraception over the counter: experiences of nonprescription users in France, Norway, Sweden and Portugal. Contraception 2003;68(2): I 17-24.

12 Bissell P, Anderson C. Supplying emergency contraception via community pharmacies in the UK: reflections on the experiences of users and providers. Soc Sci and Med 2003;57:2367-2378.

13 BPAS. Pharmacy provision of emergency contraception: a mystery shopper survey. 2018. BPAS.

I4 Eades CE, Ferguson JS, O'Carroll RE. Public health in community pharmacy: A systematic review of pharmacist and consumer views. BMC Public Health 20 I I; I I: 582. 
15 Dewsbury C, Rodgers RM, Krska J. Views of English Pharmacists on Providing Public Health Services. Pharmacy 20I5; I3;3(4): I54-I68.

16 Melton BL, Lai Z. Review of community pharmacy services: what is being performed, and where are the opportunities for improvement? Integr Pharm Res Pract 2017;6:7989.

17 Royal Pharmaceutical Society. Oral emergency contraceptive as pharmacy medicines. 2019. https://www.rpharms.com/resources/quick-reference-guides/oral-emergencycontraceptives-as-pharmacy-medicines

18 Centre for Pharmacy Postgraduate Education (CPPE). Emergency hormonal contraception pharmacy enhanced service, Pre-workshop booklet. $201 \mathrm{I}$. https://www.cppe.ac.uk/learningdocuments/pdfs/I 730968(preworka5)\%20ehc\%20ls\%20 aug\%2020I I.pdf 